\title{
4
}

\section{Full Thickness Skin Grafts}

\author{
Saikat Ray ${ }^{1}$ and Krishna Rao ${ }^{2}$ \\ ${ }^{1}$ Department of Plastic and Reconstructive Surgery, \\ Northampton General Hospital NHS Trust \\ ${ }^{2}$ Department of Plastic and Reconstructive Surgery, \\ Sheffield Teaching Hospitals NHS Trust \\ United Kingdom
}

\section{Introduction}

Skin is the largest organ of the human body and has a number of essential functions. It forms a protective barrier against pathogens and the internal and external environment. It acts as a water resistant barrier so that essential nutrients are not washed out of the body. It provides a dry and semi-permeable barrier to fluid loss. Langerhan cells in the skin are part of the adaptive immune system . The skin plays an important role in sensation and contains a number of nerve endings that respond to heat and cold, vibration, pressure, touch and pain. Thermoregulation is another essential function of the skin. Finally, the skin also plays a vital role in the synthesis of Vitamin D. It is imperative that skin cover is preserved in humans for all the reasons mentioned above.

Skin grafts are harvested from a donor site and transferred to a distant recipient site (bed) without carrying its own blood supply. The graft relies on new blood vessels from the recipient site bed to be generated (angiogenesis).

Full thickness skin grafts consist of the entire epidermis and dermis. These grafts are a simple and reliable method of achieving closure of skin defects where primary closure or healing by secondary intention is not possible. Full-thickness skin grafts are generally used to resurface smaller defects because they are limited in size. They are invaluable for reconstruction of defects where good cosmetic outcome or a durable skin cover is necessary. Common areas include defects on the face, scalp and hand, often following excision of skin lesions. A suitable well vascularized bed is necessary for full-thickness skin graft take. 'Take' is the process which results in the reattachment and revascularization of the skin graft.

\section{Mechanisms of skin graft take}

There are 3 predictable stages of skin graft take which include.

\subsection{Plasmatic imbibition}

Initially, the skin grafts passively absorbs the nutrients in the wound bed by diffusion. Imbibition prevents the graft from desiccation and keeps the graft vessels patent. This enables the graft to survive the immediate post graft ischaemic period, which is for an undetermined period of time that varies according to the wound bed. This may be upto 24 
hours for a graft placed on a bed that is already proliferative and 48 hours for a graft covering a fresh wound.

A graft can tolerate an ischemic interval when placed on a poorly vascularized bed. Thick full thickness skin grafts appear to tolerate ischemia for up to 3 days while thin full thickness skin grafts survive for up to 5 days. Split-thickness grafts take well even after 4 days of ischemia. Grafts can add as much as $40 \%$ to their pre-graft weight through fluid movement from recipient bed to graft and hence appear plump during this time.

\subsection{Inosculation and capillary ingrowth}

By day 3, a fine vascular network is established in the fibrin layer between the graft and its recipient bed capillary buds from the recipient bed line up with graft vessels on the underside of the dermis to form open channels. Blood flow is established and the skin graft becomes pink. Proliferation of fibroblasts and deposition of collagen to replace the fibrin maintains skin graft adhesion to its bed. Attachment strength increases rapidly, and anchorage can be provided within 4 days.

\subsection{Revascularization}

By day 5, new blood vessels grow into the graft and the graft becomes vascularized. The connection between graft and host vessels develops further as the graft revascularizes. Newly formed vascular connections continue to differentiate into afferent and efferent vessels. The fifth or sixth post graft day notes the presence of lymphatic drainage. The graft reduces in weight until it reaches its pre-graft weight by the ninth day.

\section{Harvesting a full thickness skin graft}

Different parts of the body vary greatly in terms of the appearance, colour, texture, thickness and vascularity of skin. All of these factors are taken into account when choosing a donor area appropriate to a certain defect.

Full thickness skin grafts can be harvested from a number of areas in the body that have skin redundancy. When the face is being grafted, the posterior surface of the ear extending onto the neighbouring post auricular hairless mastoid skin provides an excellent donor site in terms of skin colour and texture. Another useful area for facial lesions is the preauricular area (Figure 1). Upper eyelid skin is useful particularly when the defect is of another eyelid. Supraclavicular skin excised from the lower posterior triangle of the neck gives reasonable colour and texture to resurface facial defects. However, this is cosmetically inferior to post auricular skin. Flexural skin including the ante-cubital fossa, groin and distal wrist crease are also used as donor sites. The main use of groin skin is where a long, narrow piece of skin is required, such as in managing flexion contractures in the hand. The formation of a noticeable scar is a realistic possibility when closing ante-cubital fossa donor areas, often resulying in scar hypertrophy when closed under excess tension. The medial arm and forearm are other commonly used areas to provide donor skin (Figure 2). Thigh and abdominal skin are good at providing skin cover for the palm of the hand. The thicker dermis from these areas also provides a good pad to withstand pressure when used on the sole of the foot. Full thickness skin grafts undergo a significant degree of primary contraction following harvest. It is useful to make a template of the recipient defect. This shape is then transferred to the donor area and extended to form an ellipse. The ellipse is ideally designed such that the 


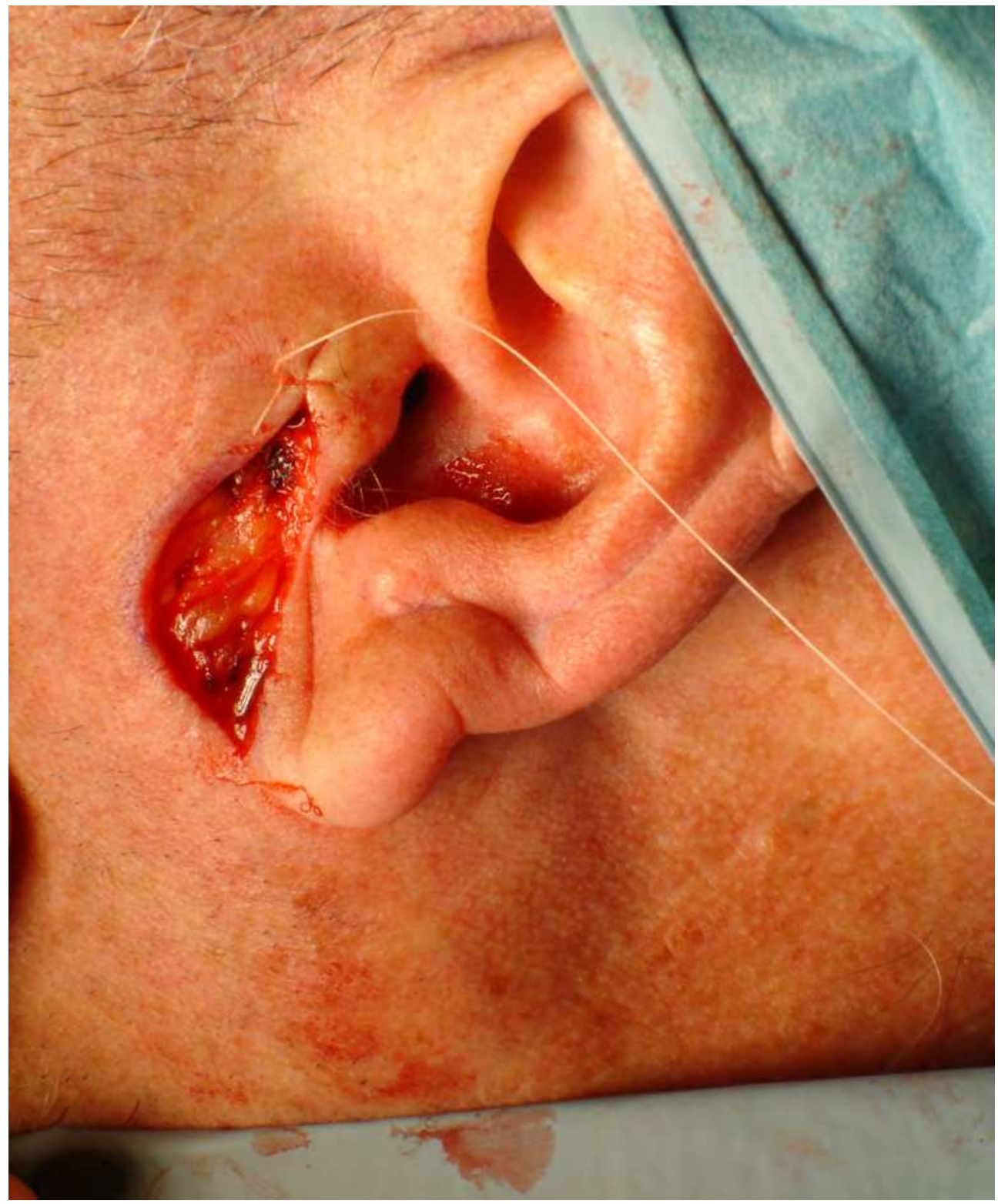

Fig. 1. Pre-auricular full thickness skin donor area. Vicryl rapide suture can be seen at the superior aspect of the ellipse to close wound 


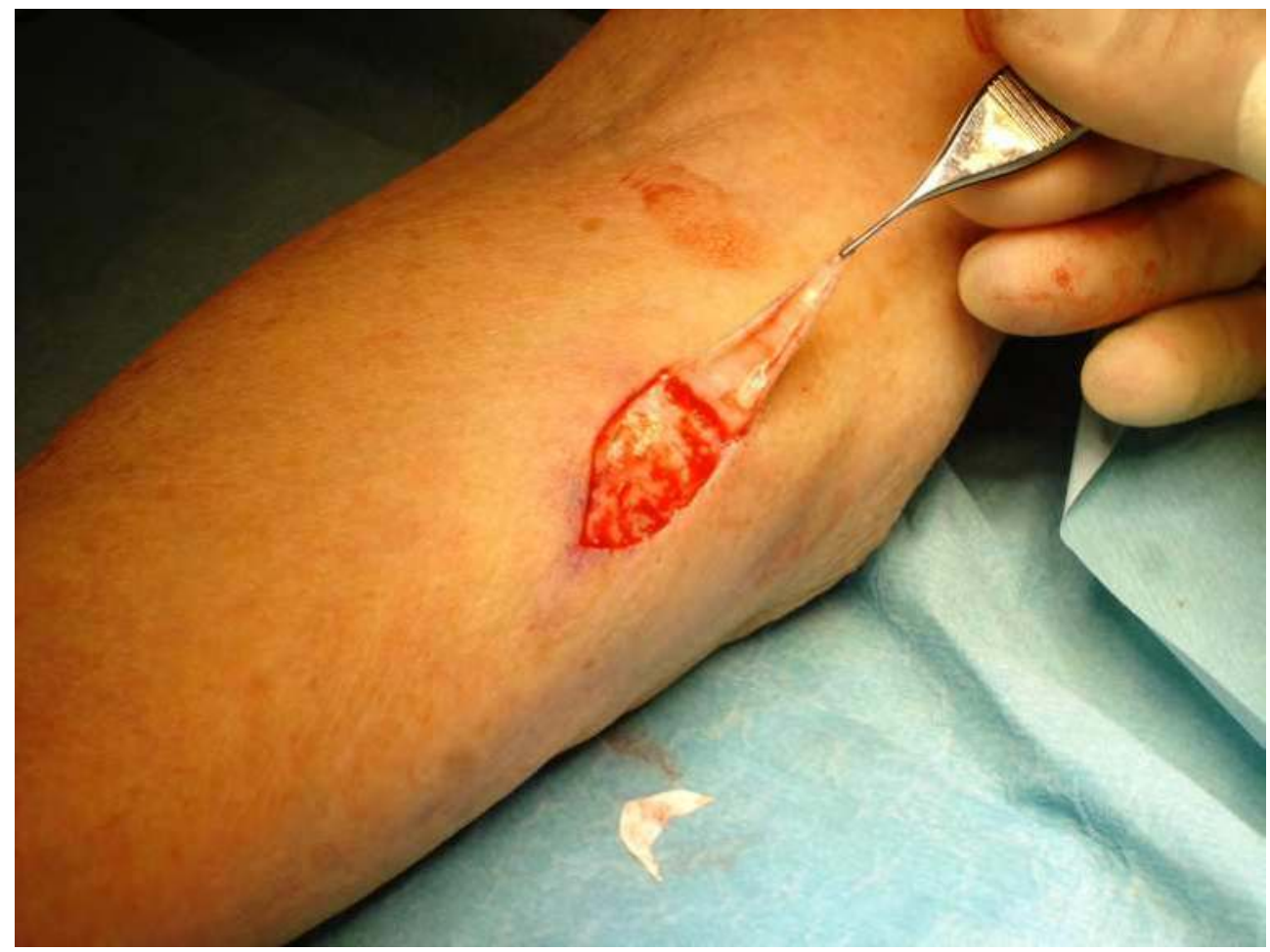

Fig. 2. Full-thickness skin graft harvest from the medial forearm donor area. Note the shiny undersurface of the graft dermis

resulting scar lies in the direction of the natural skin crease lines (Langer's lines). The graft is usually harvested with a 15 inch bladed scalpel between the dermis and the subcutaneous fat. Often, the graft is easier to cut if the area is infiltrated with fluid (1:200000 adrenaline). The full thickness skin graft leaves behind no epidermal elements in the donor site from which resurfacing can take place. For this reason, primary closure of the donor site is necessary. This is usually achieved using an absorbable suture in a single layer subcuticular stitch (Figures 3 and 4). Occasionally, a split thickness skin graft may be used to close the donor area. 


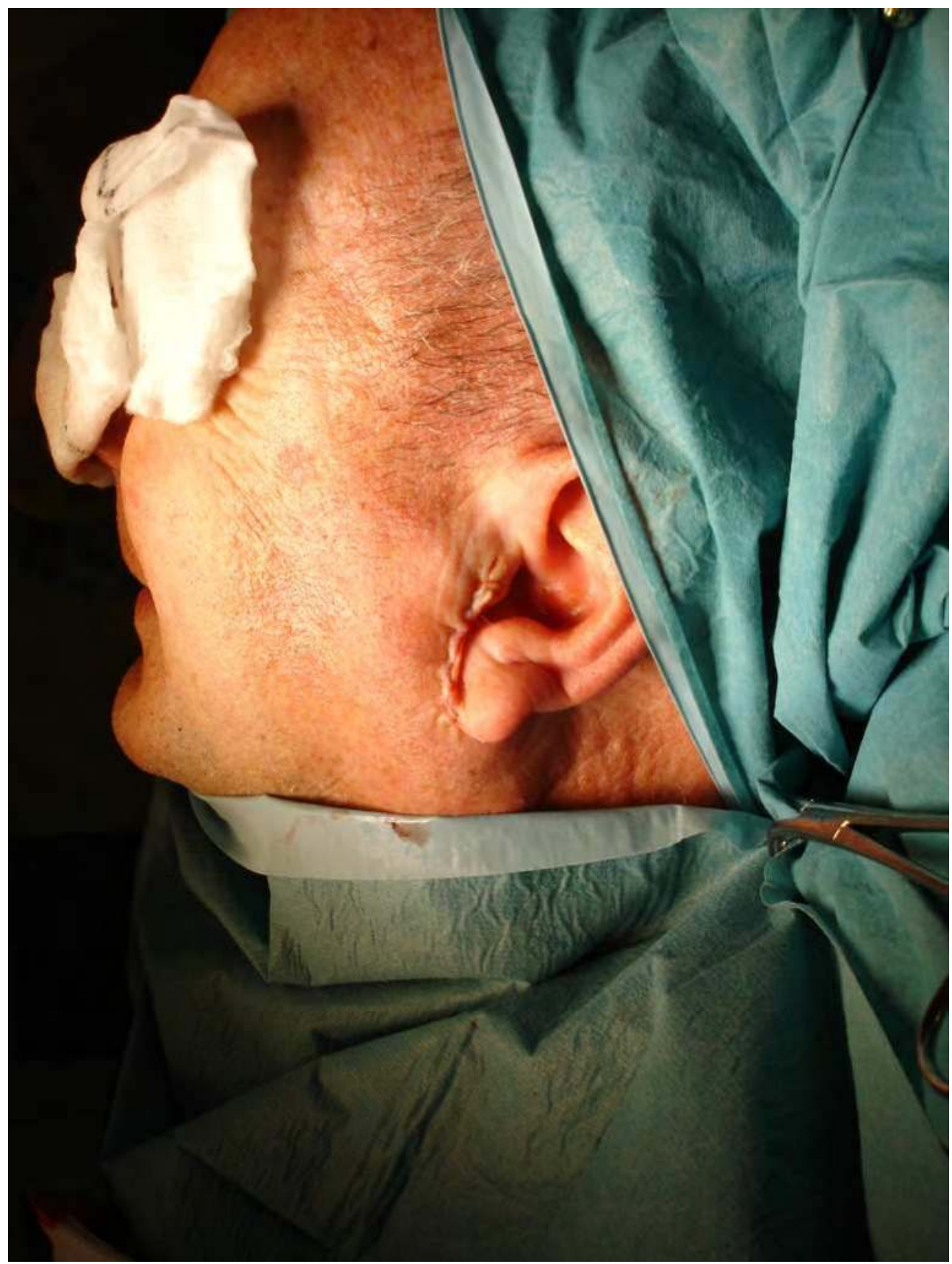

Fig. 3. Closure of pre-auricular full thickness skin donor area 


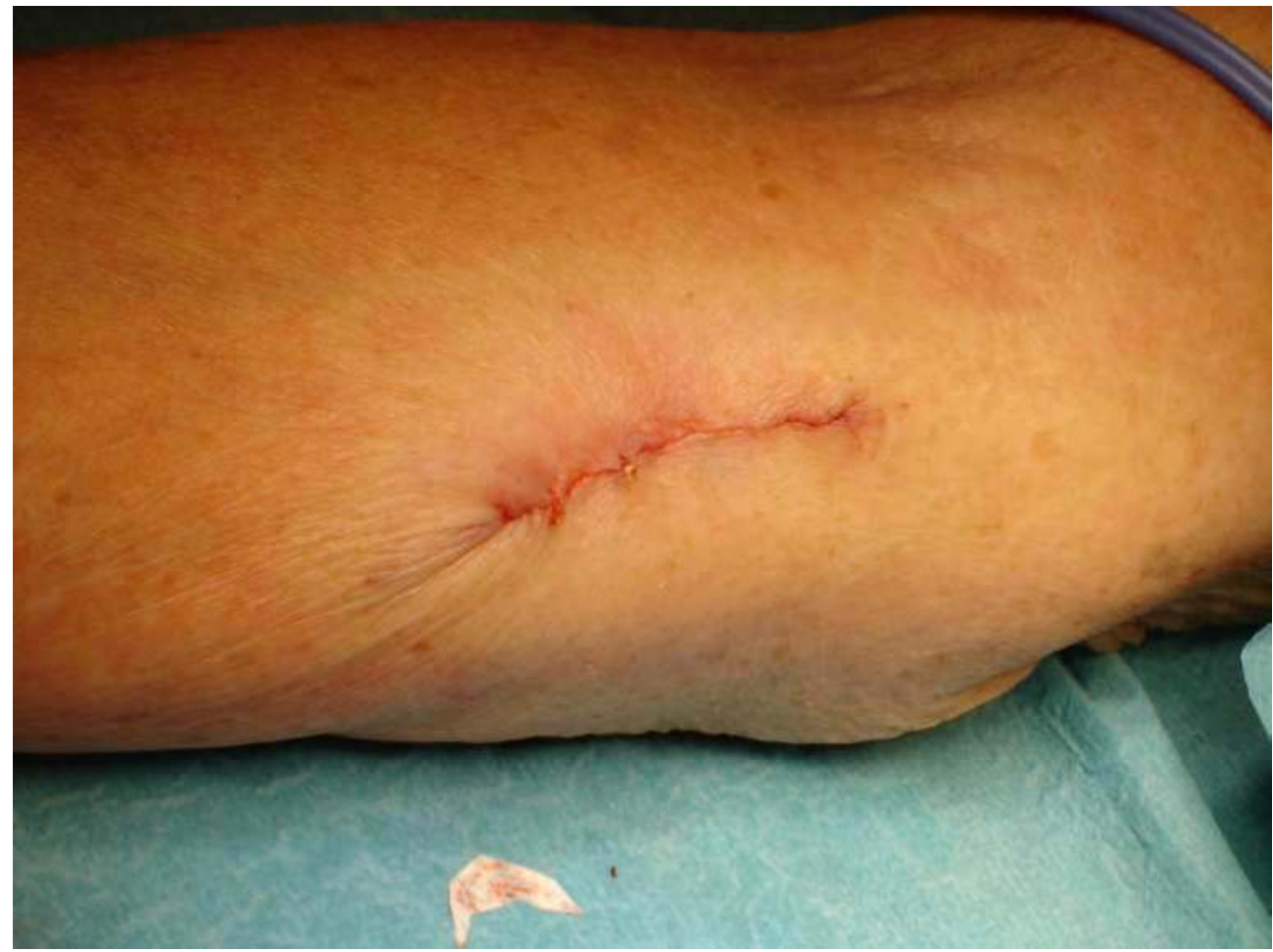

Fig. 4. Closure of medial forearm full thickness skin donor area

The graft may be further defatted, as fat is poorly vascularized and will prevent firm adherence between the graft dermis and the recipient bed. All yellow fat must be trimmed using a pair of sharp scissors until only the the shiny white undersurface of the dermis is visible.

\section{Graft inset}

A good graft inset is necessary to ensure immobilization of the graft on its bed and to prevent haematoma formation. The graft is secured onto the donor site by sutures with the dermis side down and trimmed to fit (Figures 5 and 6). A non-adherent layer such as a jelonet dressing is also necessary to facilitate easy separation of the dressing.

A number of techniques can be used which include tie over dressings, foam bolsters and quilting sutures. The full thickness skin graft is sutured to the wound edges circumferentially with independent sutures which are cut long. A tie-over dressing using a piece of gauze or wool soaked in proflavin is applied and the suture ends tied to secure the dressing. This helps to fix the graft and reduces shear forces (Figure 7). Alternatively, additional pressure and immobilization can be achieved using a foam bolster secured with sutures or staples (Figure 8). Quilting sutures applied between the graft and the bed ensure good contact between the graft and the wound bed, while ensuring immobilization. 


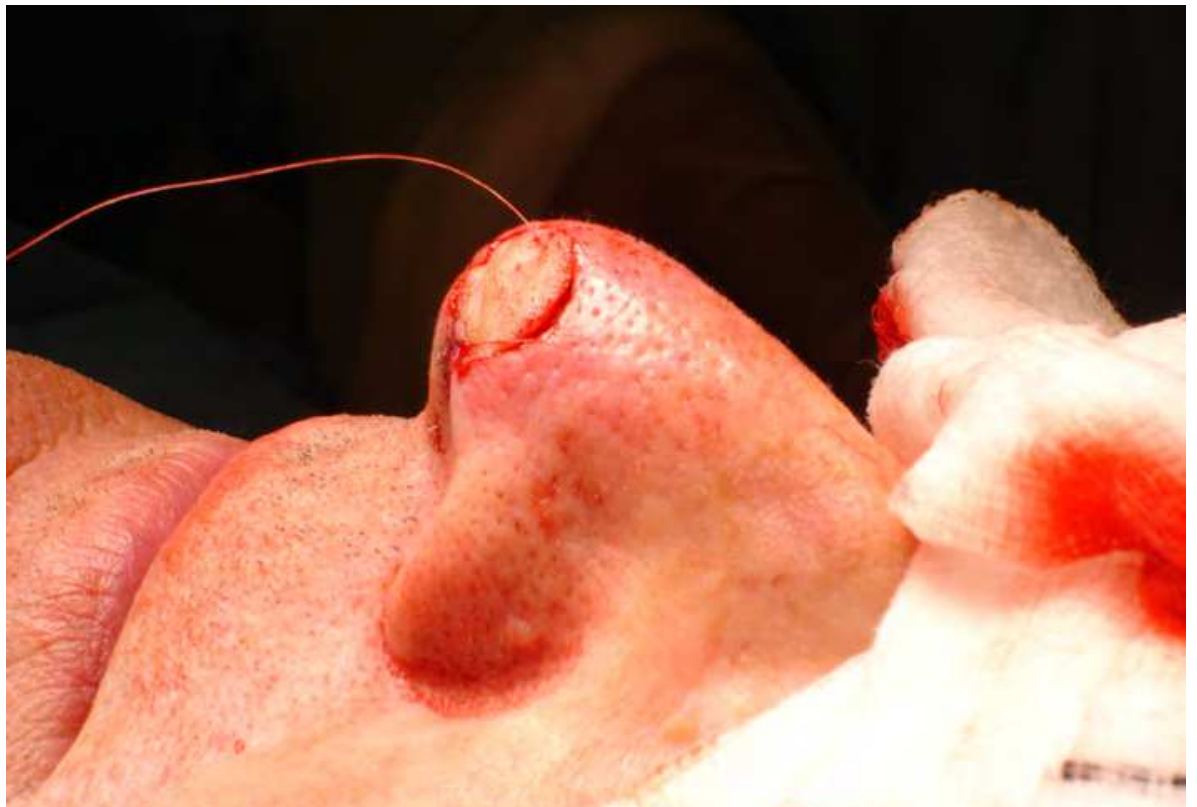

Fig. 5. Full thickness skin graft inset onto nose

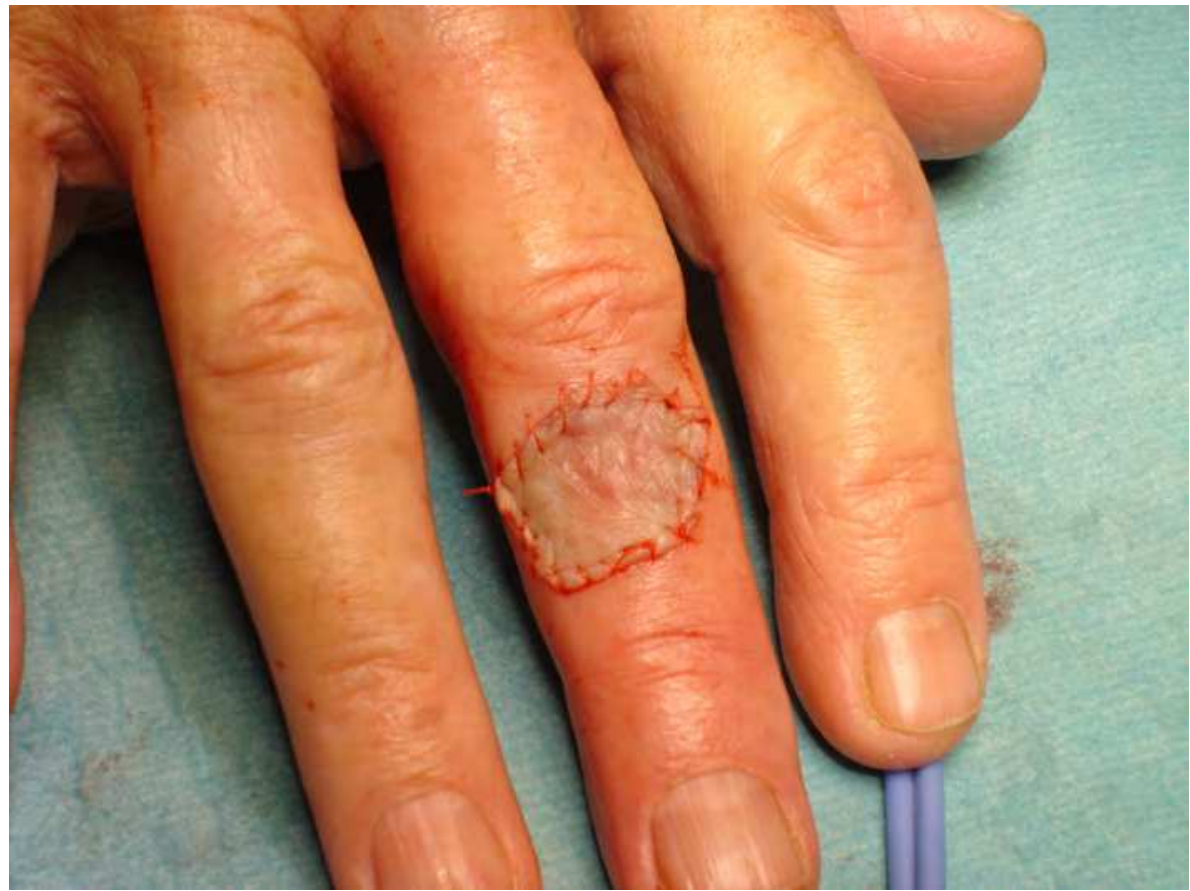

Fig. 6. Full thickness skin graft inset onto dorsum of finger 


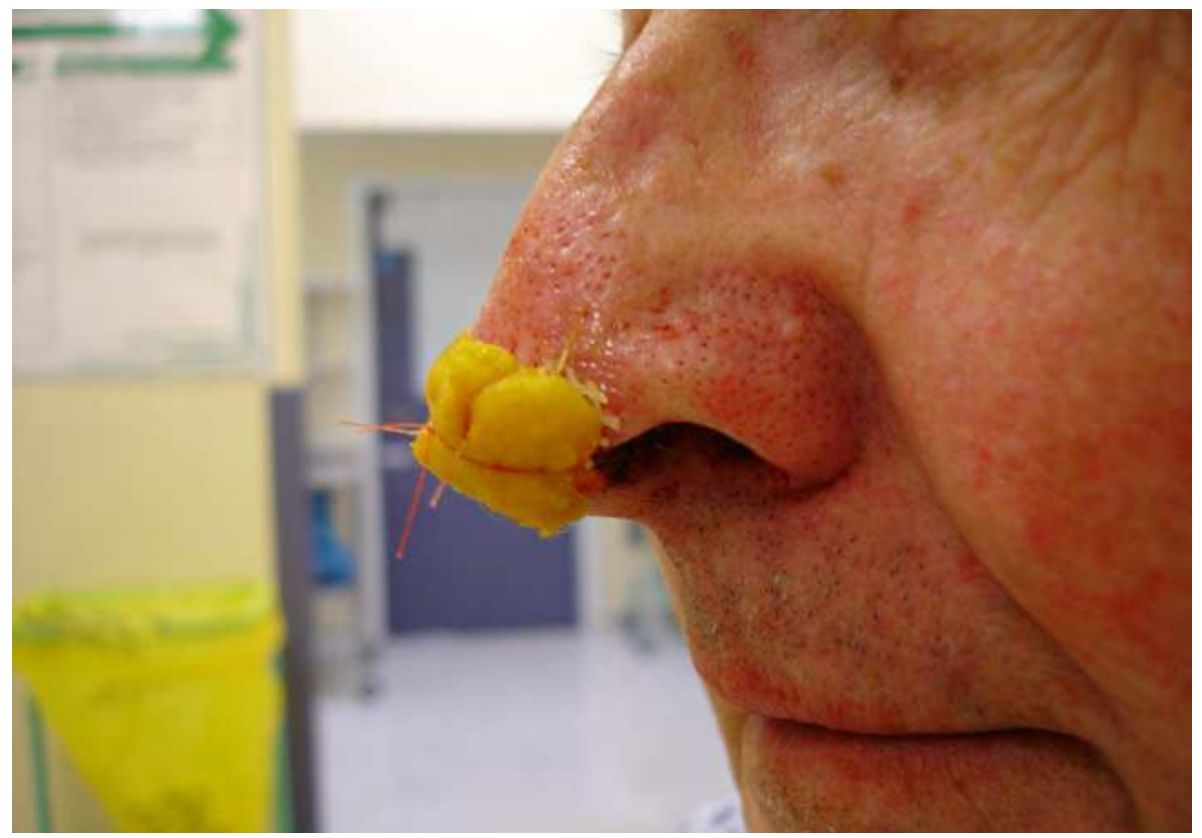

Fig. 7. Tie over dressing secured with sutures over full-thickness skin graft on nose. Note the presence of a non-adherent dressing (jelonet) between the proflavin wool and the graft

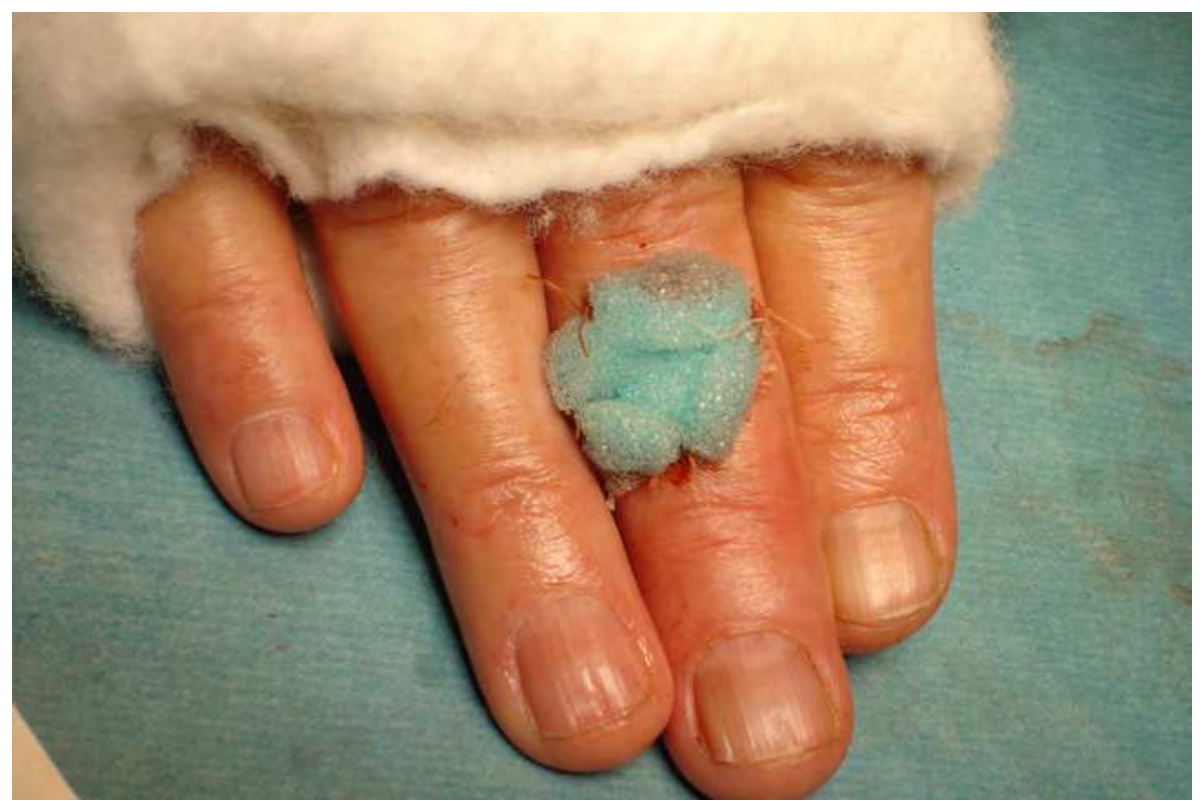

Fig. 8. Foam bolster dressing secured with sutures over full-thickness skin graft on dorsum of finger 


\section{Factors affecting graft survival}

Before application of the graft, it is imperative that measures are taken to give the full thickness graft the best chance of survival. These include the following -

\subsection{Healthy wound bed}

Skin grafts rely on the underlying vascularity of the bed to maintain cellular respiration. Devascularized tissues, such as bone without periosteum, cartilage without perichondrium and tendon without paratenon, need an overlying layer of granulation tissue in order to be grafted. However, If the area is small, a graft may survive over bare cortical bone, cartilage or tendon by the phenomenon of 'bridging'. Bridging is where the blood supply of the neighbouring tissue is more than adequate to allow the graft in it vascularisation to 'bridge' the defect and successfully provide cover. Skin grafts can also survive on dermis, fascia, muscle and fat. Fat on the face is extremely vascular and grafts take readily. However the relatively poor vascularity of fat elsewhere limits its use a suitable surface to graft. Wounds which have undergone radiation have a compromised blood supply and may be unable to nourish a skin graft. Correction of underlying vascular problems is essential in vasculopaths with arterial insufficiency or venous stasis ulcers. Multiple surgical debridements may be required for a contaminated or chronic wound. Vacuum-assisted closure therapy or wet-todry dressing changes may occasionally be required until the recipient bed appears clean, healthy and red with punctate bleeding.

\subsection{Absence of infection}

Recipient sites must be healthy and free from infection. Bacterial levels greater than $10^{5} / \mathrm{cm}^{2}$ are clinically significant. The bacterial count may be reduced by topical or systemic antibiotics. The presence of Streptococcus pyogenes on the wound bed is an absolute contraindication to skin grafting. The exact mechanism is unknown; however, Strep species produce fibrinolysin which lyse the fibrin attachment of the graft. In large areas which need to be grafted, e.g. following burns, routine bacteriologic swab investigation is often necessary. Streptococcus pyogenes must always be eliminated with antibiotics before grafting. Infection with Pseudomonas aeruginosa may reduce graft take by $5-10 \%$. This can be treated by application of an antiseptic like chlorhexidine and removal of slough from the wound bed. Antibiotics for Pseudomonas aeruginosa are not usually necessary. Necrotic tissue must be completely debrided, as decaying tissue contains no blood supply and produces toxins that impair wound healing.

\subsection{Absence of shear}

Shear forces separate the graft from the bed and prevent the contact necessary for capillary link up and subsequent survival. Shear is minimised by using a foam tie dressing or proflavin cotton wool dressing to ensure good contact between the graft and the bed. This is until the initial fibrin adhesion has been converted into a strong fibrous tissue anchorage.

\subsection{Hemostasis}

Meticulous hemostasis is imperative during the operation in order to prevent haematoma formation (Figure 9). The operation steps should be planned to give the bed the longest time for the normal hemostatic processes to take effect. Bipolar coagulation is precise in 
controlling small bleeding vessels. Hematomas and seromas prevent contact of the graft to the bed and inhibit revascularization. They act as a block to link-up of the outgrowing capillaries. They must be drained by day 3 to facilitate graft survival.

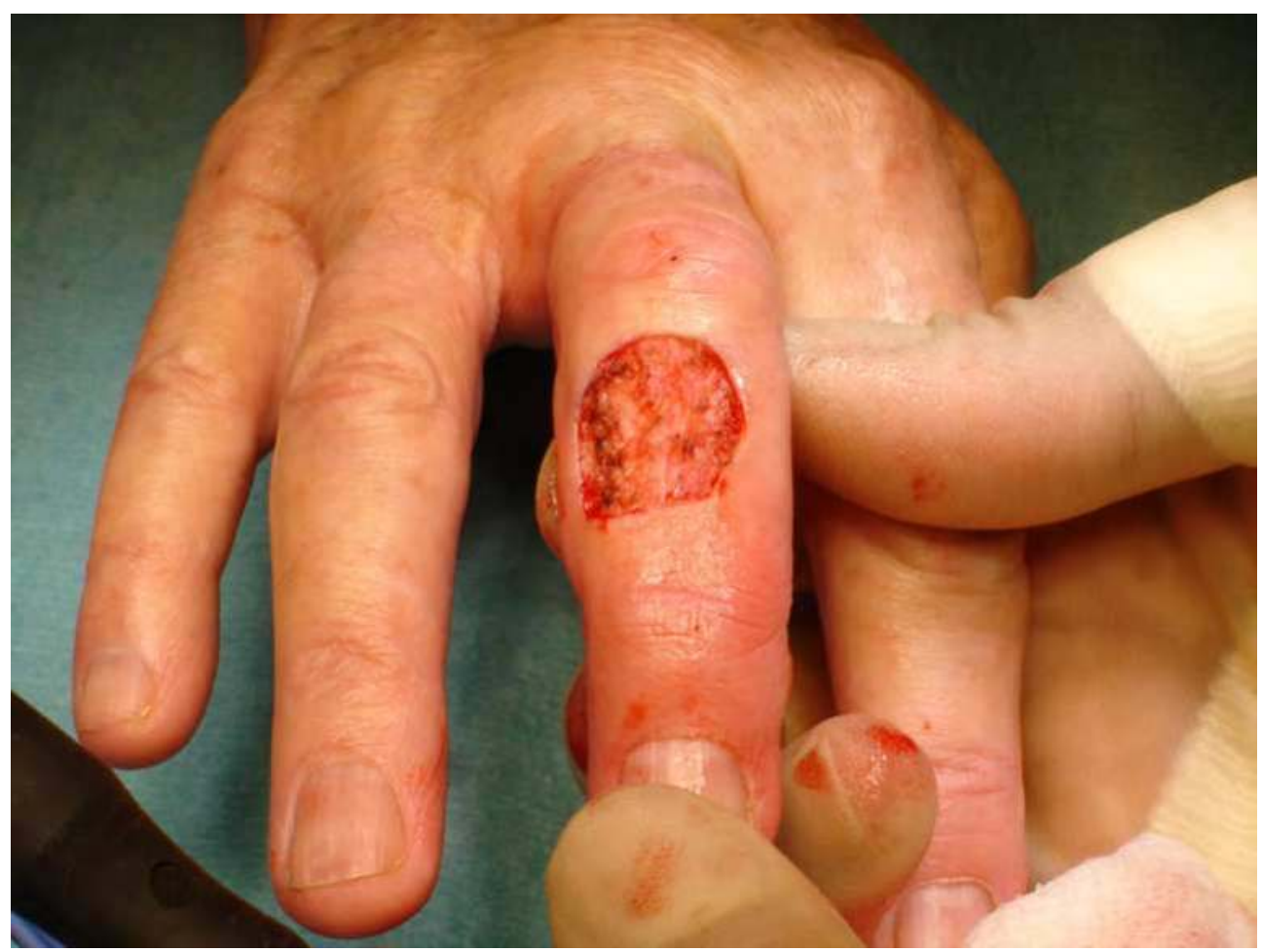

Fig. 9. Recipient 'bed' on dorsum of finger. Ensure meticulous hemostasis is achieved prior to graft

\section{Advantages}

Full-thickness skin grafts have a number of advantages over split skin grafts. When donor skin from the pre or post auricular region is used to resurface defects on the face, the colour match is usually excellent. Full-thickness grafts undergo minimal secondary contraction compared to split skin grafts. As a result, they maintain their characteristics well. This includes robustness of skin resulting in less likelihood of graft trauma. Also, a shapely contour is achieved compared to split skin grafts where clearly demarcated contours are often visibly seen, resulting in a sub-optimal cosmetic outcome and resultant patient embarrassment. A more uniform texture is achieved using a full-thickness skin graft. A major advantage is also the transference of dermal structures such as hair follicles if the 
defect is in a hair-bearing area. Finally, there is full-thickness skin graft growth potential as the patient grows.

\section{Disadvantages}

There are a few disadvantages in performing full-thickness skin grafting. Firstly, the presence of a well vascularized bed is necessary to ensure graft take and survival. Secondly, there is only a limited supply of donor skin that can be closed directly. An alternative way to close the donor area would be to utilise a split skin graft in addition to primary closure, however this results in another wound at the donor site which requires healing, as well as a sub-optimal cosmetic appearance. Finally, the transference of unwanted structures such as hair follicles may be disadvantageous if the grafted area is in a non hair- bearing region.

\section{Conclusion}

In this chapter, full-thickness skin grafts have been discussed as a simple and reliable method of skin coverage of small wounds which cannot be closed primarily. The mechanisms involved in graft take are plasmatic imbibition, inosculation and capillary ingrowth, and revascularization. There is a choice of a number of areas in the body skin grafts can be harvested from. However, the ultimate area of skin harvest is tailored to its specific destination depending on the colour match, consistency and robustness of the skin required. Particular attention must be paid to the adequate preparation of the bed to be grafted with regards to a healthy well vascularized wound bed, absence of infection, absence of shear forces and meticulous hemostasis to avoid hematoma formation.

\section{References}

Chen CM and Cole J (2007). Skin Grafting and Skin Substitutes In Practical Plastic Surgery, edited by Kryger ZB and Sisco M, pp. (145-153), Landes Bioscience, ISBN 978-157059-696-4, United States of America.

Giele H and Cassell O (2008). Plastic Surgery Science In Plastic and Reconstructive Surgery (Oxford Specialist Handbooks in Surgery), Oxford University Press, ISBN 978-0-19263222-7, United Kingdom

Granzow JW and Boyd JB (2010). Grafts, Local and Regional Flaps In Plastic and Reconstructive Surgery, edited by John Lumley, pp. (65-87), Springer, ISBN 978-184882-512-3, United Kingdom.

Hackett MEJ. (1986). Restoration of skin cover : the use of free grafts In Plastic Surgery, Rob and Smith's Operative Surgery (4th edition), edited by Barclay TL and Karnahan DA, pp. (14-27), Butterworths, ISBN 0-407-00664-8, United Kingdom.

McGregor AD and McGregor IA. (2009). Fundamental techniques of Plastic Surgery and their Surgical Applications (10 th edition), Elsevier Limited, ISBN 978044306372 5, United Kingdom. 
Thorne CH. (2007). Techniques and Principles in Plastic Surgery In Grabb and Smith's Plastic Surgery (6 th $^{\text {th }}$ edition), edited by Thorne $\mathrm{CH}$, pp. (3-14), Lippincott Williams \& Wilkins, ISBN 978-0-7817-4698-4, United States of America.

Thornton JF (2004). Skin Grafts and Skin Substitutes, Selected Readings in Plastic Surgery (Vol 10, Number 1), pp. (1-23), ISSN 0739-5523. 


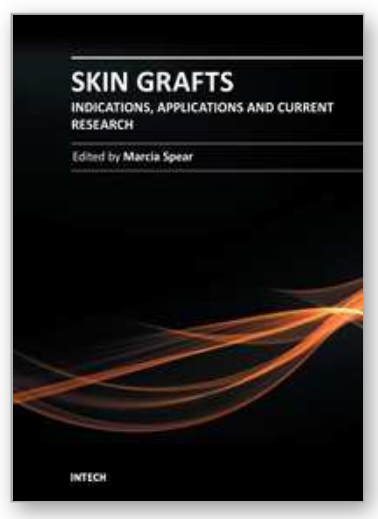

\author{
Skin Grafts - Indications, Applications and Current Research \\ Edited by Dr. Marcia Spear
}

ISBN 978-953-307-509-9

Hard cover, 368 pages

Publisher InTech

Published online 29, August, 2011

Published in print edition August, 2011

The procedure of skin grafting has been performed since 3000BC and with the aid of modern technology has evolved through the years. While the development of new techniques and devices has significantly improved the functional as well as the aesthetic results from skin grafting, the fundamentals of skin grafting have remained the same, a healthy vascular granulating wound bed free of infection. Adherence to the recipient bed is the most important factor in skin graft survival and research continues introducing new techniques that promote this process. Biological and synthetic skin substitutes have also provided better treatment options as well as HLA tissue typing and the use of growth factors. Even today, skin grafts remain the most common and least invasive procedure for the closure of soft tissue defects but the quest for perfection continues.

\title{
How to reference
}

In order to correctly reference this scholarly work, feel free to copy and paste the following:

Saikat Ray and Krishna Rao (2011). Full Thickness Skin Grafts, Skin Grafts - Indications, Applications and Current Research, Dr. Marcia Spear (Ed.), ISBN: 978-953-307-509-9, InTech, Available from: http://www.intechopen.com/books/skin-grafts-indications-applications-and-current-research/full-thickness-skingrafts

\section{INTECH}

open science | open minds

\section{InTech Europe}

University Campus STeP Ri

Slavka Krautzeka 83/A

51000 Rijeka, Croatia

Phone: +385 (51) 770447

Fax: +385 (51) 686166

www.intechopen.com

\section{InTech China}

Unit 405, Office Block, Hotel Equatorial Shanghai

No.65, Yan An Road (West), Shanghai, 200040, China 中国上海市延安西路65号上海国际贵都大饭店办公楼 405 单元

Phone: +86-21-62489820

Fax: +86-21-62489821 
(C) 2011 The Author(s). Licensee IntechOpen. This chapter is distributed under the terms of the Creative Commons Attribution-NonCommercialShareAlike-3.0 License, which permits use, distribution and reproduction for non-commercial purposes, provided the original is properly cited and derivative works building on this content are distributed under the same license. 